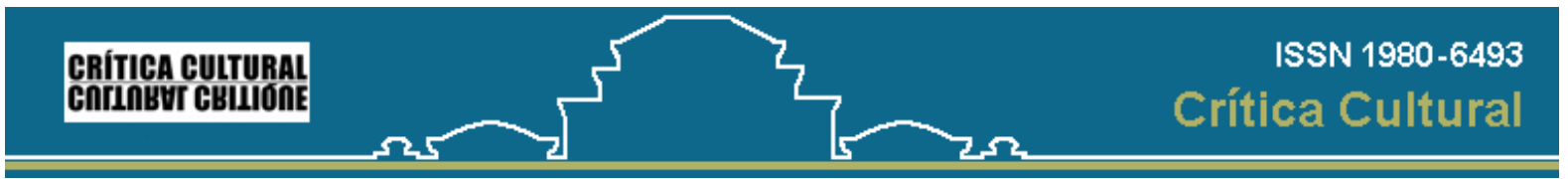

Crítica Cultural, volume 3, número 1, jan.jjun. 2008

\title{
O SEQÜESTRO DO SIMBOLISMO NA REVISTA JOAQUIM: O GRITO DO VAMPIRO CONTRA O SUSSURRO DO NEFELIBATA
}

\author{
Caio Ricardo Bona Moreira)-
}

Resumo: Proponho neste artigo uma leitura contra-modernista da posição radical da revista Joaquim contra o Simbolismo Paranaense. A revista, fundada em 1946, pelo escritor curitibano Dalton Trevisan, circulou até 1948, período de ascensão do existencialismo no cenário literário do pós-guerra. Depreende-se de sua posição autonomista o desejo de iniciar oficialmente a literatura no Paraná. 0 periódico recusa 0 simbolismo, pois foi considerado por Dalton como uma literatura que não sintonizou a sua produção com os problemas do homem e do mundo. Pretendo observar que a questão da gênese tratada como origem pela revista não se sustenta como fundamento para práticas críticas.

Palavras-chave: Revista J oaquim, Modernismo, Simbolismo Paranaense.

Se ao Senhor a vingança pertence,

por que devo eu apontá-lo,

falso vendilhão de rimas?

Beletrismo paranista

- ó sagrado templo das musas pernetas.

Dalton Trevisan

\section{Introdução}

No ensaio O seqüestro do barroco na formação da literatura brasileira: o caso Gregório de Mattos, Haroldo de Campos, tocado por questões benjaminianas, como o conceito de alegoria e o de pervivência das obras literárias, questiona a ausência - ou melhor, o seqüestro - do Barroco, no livro Formação da Literatura Brasileira, de Antonio Candido. O seqüestro faria parte de um problema de origem, constante na literatura brasileira. Haroldo, pensando no logocentrismo platonizante, que levou Derrida a escrever Gramatologia, afirma que estaríamos, assim, diante de uma metafísica ocidental da presença, já que a necessidade de uma origem estaria ligada à necessidade de um pai fundador. $\mathrm{E}$ justamente a partir da perspectiva desconstrucionista que Haroldo começa a examinar o modelo de leitura adotado por Antonio Candido.

0 modelo de história que envolve a tese da Formação da Literatura Brasileira estaria concentrado numa teleologia que, além de desenvolver uma seqüência acabada de eventos, necessitaria de um começo, uma arké, que justificasse o seu surgimento. Esse começo é identificado por Candido na literatura árcade de Cláudio Manuel da Costa. A metáfora que definiria o desenvolvimento da tese é organicista e estaria ligada à idéia de que a literatura brasileira seria uma espécie de ramificação da literatura portuguesa e, por mais fraca que se apresente, merece carinho, pois é aquela que temos.

Procurando explorar uma visão que colocasse em xeque a concepção de história retilínea, Haroldo não hesitou em "alfinetar" o olhar romântico de Candido. O seqüestro do movimento não seria perdoado pelo poeta concretista que, na esteira de outros teóricos latinoamericanos como Lezama Lima, enxergava no Barroco o "começo genial" da literatura das Américas.

Apesar da filiação de Haroldo em um programa que poderíamos chamar de benjaminiano, em que o tempo deveria ser pensado dentro de uma outra lógica, é importante perceber que a metáfora orgânica estaria implícita também na perspectiva de Haroldo, já que adotar Gregório de Mattos, e não a literatura árcade como legítimo começo, representa uma queda na própria armadilha, pois a necessidade de um pai fundador permanece. Em Haroldo, ele ainda existe, só que agora é outro, Gregório de Mattos.

Talvez a lição de Derrida não tenha sido assimilada e o poeta não tenha percebido o jogo das diferenças, em que a figura de um pai fundador seria uma ilusão. 0 que faz com que Haroldo, ao tentar mostrar que o Barroco nos levaria de volta às musas, não consiga sair da lógica da modernidade.

Walter Benjamin, na Origem do Drama Barroco Alemão, apresenta uma noção de origem bastante diferente das concepções tradicionais. Para ele, ela não significa uma gênese: "A origem, apesar de ser uma categoria totalmente histórica, não tem nada a ver com a gênese. $O$ termo origem não designa o vir-a-ser daquilo que se origina, e sim algo que emerge do vir-a-ser e da extinção" (BENJ AMIN, 1984, p. 67). Definir uma gênese seria, então, abandonar o conceito de origem benjaminiano, caindo na busca de uma arké. Estaríamos, então, diante de um problema de tempo, e da impossibilidade de reduzi-lo à história. Impossível pensar no originário sem levar em conta que ele é pautado pela restauração e pela reprodução, sendo, portanto, incompleto e inacabado.

Mas citamos o seqüestro apenas para chegar a outro, não menos confuso na busca de um pai fundador. Falo da postura da revista

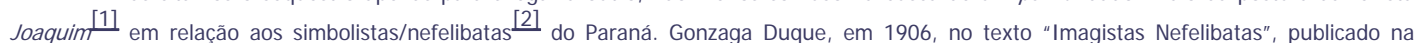
revista Kosmos, comenta o termo nefelibata e a carga pejorativa que recebeu ao ser aproximado do universo simbolista: "Esquisito, estranho, inédito, este termo valia por uma troça, siflava e demolia. Era um cartucho de alvaiade. Verdadeiramente não ofendia, porque, por sua composição grega, queria dizer habitante das nuvens e na sua aplicação - pensamento inacessível ao comum dos homens, transcendentalismo. Mas, empregado sem o conhecimento do seu valor, é tão ridículo como uma carapuça de jornal velho. (...) Chamemo-la nefelibata (a estética simbolista), mas com um suave sorriso que não humilhe nem hostilize" (DUQUE in CAROLLO, 1980, p. 137).

O que proponho aqui é uma leitura contra-modernista da posição autonômica da revista fundada por Dalton Trevisan na segunda metade da década de 40. A discussão vanguardista que permeia o horizonte da sua linha editorial aponta sem recuo para um "novo começo" à medida que se afasta radicalmente de um passado considerado inconseqüente e estéril. O periódico fora saudado com entusiasmo por Carlos Drummond de Andrade e Antonio Candido, e se posicionou violentamente contra a glorificação de poetas como Dario Vellozo, Emiliano Perneta e outros da mesma geração. Dalton exigiu, acima da música etérea dos pinheirais, a voz de um novo tempo, uma voz que não declinasse da "responsabilidade na marcha dos acontecimentos".

De fato, a gênese estaria voltada para o cenário paranaense e seria considerada por Dalton como inexistente até o nascimento de Joaquim. A revista estava interessada nas discussões contemporâneas que permeavam a literatura e as artes plásticas. Basta lembrar que nela foram publicadas traduções pioneiras de James J oyce, Virginia Woolf, e Proust.

\section{J oaquim contra os excessos dos simbolistas}

No texto "Contra el exceso: lecturas del modernismo y el neobarroco en la Argentina", Ana Porrúa analisa o quadro de leitura que a

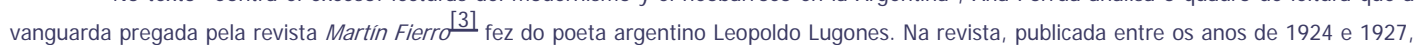
Porrúa encontra algumas das mais severas críticas endereçadas a ele. Numa delas, Leopoldo Marechal o chama de um "frio arquiteto da palavra". Isso por Lugones operar com o excesso de rimas e a primazia de um sistema retórico. Para Marechal, o uso da rima estaria associado ao desastre da imagem, ao contrário do verso livre que seria valorizado como uma forma ideal. A poética do excesso, presente no excesso de rimas, teria como efeito uma falta. Caberia perguntar: Não seria a posição da vanguarda algo extremamente repressivo?

Ana Porrúa atenta para o fato de que a vanguarda lê o que lhe é absolutamente legível: 
A vanguarda a que se refere Porrúa poderia ser estendida para outras vanguardas. A posição dogmática da revista Martín Fierro em relação ao modernista Leopoldo Lugones é semelhante ao gesto tipicamente modernista levantado pela revista Joaquim em relação ao simbolismo. E não menos efusivo é o seu gesto. No primeiro número, já ficava explícita a bandeira: pensar nos rumos que a literatura estava tomando e na necessidade de reconciliar o escritor com a experiência, ou seja, recolocar a vida na arte. Com essa alegação procuravam justificar a recusa do simbolismo como começo autorizado. 0 texto intitulado "Manifesto para não ser lido", o primeiro texto que circulou na revista, fora confeccionado à maneira dos ready-made, de Duchamp, a partir de fragmentos de Verlaine, Gide, Maiakóvski, Sergio Milliet, entre outros. Os efeitos de sentido desencadeados pela montagem parecem colocar os escritores a serviço de uma estética existencialista que não poderia ceder aos encantos de uma literatura não sintonizada com os problemas do homem e do mundo.

Não podemos desconsiderar o fato de que o surgimento da Joaquim se dá num momento crucial da arte, falo do final da Segunda Guerra Mundial. Na época, Poty visitara no Rio de Janeiro a exposição de "arte degenerada", organizada pelo III Reich e a exposição de arte francesa, que tentava traçar um esboço das linhas que guiariam o desenvolvimento artístico na Europa e no mundo depois da Grande Guerra. 0 contato com o universo literário, por meio das revistas, exposições e viagens, era uma possibilidade de inserir Curitiba num ambiente artístico que transcendesse o "provincianismo" reinante, ou o "beletrismo paranista 2 ". Poty foi um dos seus representantes, não hesitando em problematizar a pintura regionalista e observar a ausência de experimentações estéticas no Estado.

Em março de 1947, no número 9 da revista, o editorial intitulado "A geração dos vinte anos na ilha" criticava os escritores simbolistas da cidade. Foi justamente por furtarem-se do tempo, inserindo-se numa perspectiva anacrônica, que abandona a progressão linear temporal, que os simbolistas seriam seqüestrados pela revista Joaquim:

0 grave erro dos lírios foi o de, além da traição a si mesmos, traírem a seu tempo. Não serão perdoados por isso. Só à luz de uma lua de rua 15 é que floresciam os lírios e o novo dia os matou em pleno coração. Nossa geração, que reclama o seu direito de influir no destino do mundo, jamais fará arte paranista, no mau sentido da palavra. Ela fará simplesmente arte. Por tudo, a literatura paranaense inicia agora (TREVISAN, 1947, p. 3).

Friso a última frase: "Por tudo, a literatura paranaense inicia agora. Estava marcada então a pedra fundamental da literatura paranaense na invenção do começo. Caberia à revista levar o moderno para o inculto e arcaico.

A rebeldia acontece também no campo das artes visuais. Poty Lazzarotto, que estudara na Escola Nacional de Belas Artes, e Guido Viaro, que foi professor da Escola de Música e Belas Artes do Paraná, são apresentados como a grande expressão paranaense dos novos tempos. No artigo "Viaro, hélas... e abaixo Andersen", presente no número 7 da publicação, Dalton defende o banimento de uma tradição das artes plásticas, pautada na pintura de Andersen - um norueguês que veio para o Brasil no final do século XIX, e fora considerado até então uma referência na pintura paranaense. Contra Alfredo Emílio Andersen, a valorização do trabalho de Guido Viaro, um italiano que estudara na Academia de Belas Artes de Veneza, na Academia de Bolonha, e que se instalara na década de 30, em Curitiba: "Entre Andersen e Viaro nós, os moços, já fizemos a nossa escolha: só nos servem, não os mortos, mas a nós os vivos, que criam a arte nova dos tempos novos" (TREVISAN, 1946a, p. 10).

Posição semelhante a do artigo sobre Andersen e Viaro é encontrada no texto "Emiliano, poeta medíocre", publicado no segundo número da revista:

Ele (Emiliano) fez uma poesia de casinha de chocolate, desligada da vida, onde não há lugar para as asas de um pássaro, o grito de um humano amor, o riso de uma criança ao sol, o sonho de saúde de um moço convalescente. A sua experiência poética foi uma experiência frustrada, em todos os sentidos (...). Não fez uma poesia essencial, bofé! Ele situa-se nos antípodas da verdadeira poesia, e cujos versos chinfrins não nos põem aproximar do coração selvagem da vida, apenas dela nos afastam ("tantas que adorei e não amei nenhuma"), essa sua versalhada farinhenta de que o primeiro pé de vento já derruiu os castelos altíssimos (TREVISAN, 1946, p.16)

A revista Joaquim, que contou com o apoio de Antonio Candido, transcreveu seu artigo "Ioaquim, a irreverente e a heróica", publicado inicialmente nos Diários Associados, em que o crítico cumprimenta os moços da revista e deprecia o simbolismo local:

De lá, com efeito, partiu um dos momentos mais medíocres que a tem infestado, apadrinhado por Nestor Victor, Rocha Pombo, Emiliano Perneta e logo acolitado por uma série de então jovens poetas e escritores. (...) Os jovens de "JOAQUIM" ("em homenagem a todos os Joaquins do Brasil", diz a epígrafe, que vale um tesouro...) me parecem o oposto dessa literatura de raio-de-luar. Têm músculos para a luta e olhos abertos para a vida. Tomara que possam levar a cabo a sua obra de generosa profilaxia (CANDIDO, 1946, p. 11).

Sintetizar o trabalho desenvolvido pelos simbolistas do Paraná como meramente uma "literatura de raio-de-luar" é desconsiderar o fato de que nem todos seus escritores praticaram-na, no sentido apresentado pelo crítico. 0 equívoco é o resultado de uma classificação que pretende colocá-los numa cultura literária fechada, como se essa cultura realmente pudesse existir. Nota-se que uma classificação simplista como essa não conseguiria ler os textos simbolistas do final do século XIX e do início do século XX de outra maneira.

Um dos únicos textos que se referem positivamente ao movimento é um trecho do ensaio "Raízes do simbolismo no Paraná", de Temístocles Linhares, presente no mesmo número em que a revista publicou um artigo do arquiteto Oscar Niemeyer, que ainda não tinha projetado Brasília, símbolo da arte moderna brasileira. A presença do arquiteto não é fortuita e assinala a perspectiva autonômica que pautou a Joaquim. 0 que a maioria dos artigos sugere é que os simbolistas não mereceriam lugar no panteão curitibano pela "forma" de sua poesia. 0 argumento já serviria para mostrar que o que estaria em jogo, então, seria uma concepção que entende a poesia como forma e não como força, uma atitude tipicamente modernista.

No artigo "A aporia da leitura", Raul Antelo propõe uma leitura contra-modernista do modernismo. 0 crítico argentino apresenta para o poema Aporo, de Carlos Drummond de Andrade, uma leitura diferente daquela que o vê como uma representação do popular como uma totalidade sem divisão. Para ele o poema deve ser lido como um exemplo da fratura biopolítica dominante na sociedade moderna. Tal leitura, segundo Antelo, não deve ver o poema como uma forma mas como uma força:

A força não é singular como a forma. Ela sempre se define em relação a outras forças, donde o conceito de força nos remete diretamente ao de pluralidade Assim sendo, não é mais possível, como querem as abordagens modernistas, imanentes e universalistas, referir-se à força em singular, ora como "obra prima", ora como "regime canônico de leitura". A força é o poder de um sujeito soberano, mas também é o objeto sobre o qual esse domínio é exercido. Portanto, uma força define-se como uma relação entre forças. Ela é uma pluralidade que sempre busca, passivamente, ser afetada por outras forças mas quer, simultaneamente, incidir ativamente sobre outras forças. Em suma, a força está sempre no meio do caminho, no entre-lugar de determinação e desejo (2003, p.39).

Emiliano Perneta, em 1897, escreve um texto sobre o poema Alma Penitente, de Dario Vellozo. A crítica só seria publicada em 1899 no jornal Club Curitibano. Nela, Emiliano confessa que a batalha da arte é mais sangrenta e terrível que todas as memoráveis batalhas de César e Alexandre: "Não basta ter muito talento, é necessário também um esforço sobre-humano para vencer o demônio instigante da forma, para ver florescer e abrir ao sol a flor de luz doentia da Quimera" (PERNETA in CAROLLO, 1980, p. 65). Além de perceber que Dario adquire o status de um alquimista, para quem a força da metamorfose suplanta a noção da forma, Perneta argumenta que nos símbolos do poema o que se revela não é só nuvens e maravilhas, mas "a angústia e a ânsia dos que palmilham a terra na solidão imensa de Anjos Proscritos, todas as explosões coléricas, enfim, de uma luxúria insatisfeita no efêmero orgulho astral da carne" (idem, p. 64).

A posição de Dalton Trevisan, presente no artigo "Emiliano, poeta medíocre", reflete o motivo do gesto: "O importante foi a decisão de romper com o passado, nas suas tradições estéreis. É, pois, uma geração sem medo" (TREVISAN, 1946, p. 3). É que a geração da Joaquim, filha da segunda Guerra, optou por não se esquivar dos acontecimentos. A filosofia fenomenológica e existencial seria, assim, base para a tentativa de reconciliação do artista com o mundo.

Ao invés de tentarmos definir aqui a fenomenologia, tal como fora proposta por Husserl, talvez fosse melhor seguir o conselho de Susan Buck-Morss [5] abandonar a tarefa e ir ao cinema. Contentemo-nos com o argumento de Merleau-Ponty, que entende a fenomenologia como uma filosofia que repõe as essências na existência, não acreditando que se possa compreender o homem e o mundo de outra maneira 
senão a partir de sua "facticidade" (MERLEAU-PONTY, 1999). Impossível estocar o conhecimento, impossível a própria possibilidade de conhecimento antes da experiência.

O artigo "Romance e Metafísica", de Merleau-Ponty, publicado na revista curitibana em outubro de 1947, tenta esboçar uma aproximação da filosofia com a literatura a partir da possibilidade de um contato com o mundo que "precede a todo pensamento sobre 0 mundo" (MERLEAU-PONTY, 1947, p. 4). O que faz com que, segundo o filósofo, o trabalho da filosofia e da literatura não possa mais ser pensado separadamente. A reflexão existencialista seria, então, prioritária para o abandono do programa simbolista, que para os "novos" pecou por trocar o mundo pela torre de marfim. Uma literatura que não tratasse, assim, do mundo real, não seria considerada arte. Mas o que passa despercebido aos olhos do periódico é o fato de que o próprio real é pura potência, é da ordem do por vir, nunca estando pronto, sendo assim uma espécie de fantasma. Encarar os pontos a partir de sua lógica vanguardista seria operar num regime quase opressor. 0 modernismo se tornou autoritário justamente quando a vanguarda se tornou prescritiva. idéias:

Rancière, em A Partilha do Sensível, comenta a propensão pedagógica da vanguarda, pensando em duas posições que operam suas

A noção de vanguarda define o tipo de tema que convém à visão modernista e própria a conectar, segundo essa visão, o estético e o político. Seu sucesso está menos na conexão cômoda que produz entre a idéia artística da novidade e a idéia da direção política do movimento do que na conexão mais secreta que opera entre duas idéias de vanguarda. Existe a noção topográfica e militar da força que marcha à frente, que detém a inteligência do movimento, concentra suas forças, determina o sentido da evolução histórica e escolhe as orientações políticas subjetivas. Enfim, há essa idéia que liga a subjetividade poética a uma determinada forma-partido, do destacamento avançado extraindo a capacidade dirigente de sua capacidade para ler e interpretar os signos da história. E há essa outra idéia de vanguarda que se enraíza na antecipação estética do futuro, segundo o modelo schilleriano (RANCIÉRE, 2005, p. 43).

A conclusão de Rancière, centrada na idéia da emergência de um regime estético, considera o fato de que o sentido da vanguarda deve estar não do lado dos destacamentos avançados da novidade artística, mas do lado da invenção de formas sensíveis e dos limites materiais de uma vida por vir.

As vanguardas falham porque trabalham com a coerência, com a homogeneidade, ao passo que deveriam lidar com a disseminação. Assim, o escrito não estaria mais centrado na idéia de obra, mas na idéia de texto, como soube assinalar Roland Barthes.

A idéia de uma proposta doutrinária, que seria pautada num paradigma estético desenvolvido pela Joaquim, estaria bastante distante de uma perspectiva pós-autonômica.

Se, ao contrário, optássemos por pensar a partir de uma lógica da singularidade, perceberíamos que a própria noção de arte sofreria uma substancial transformação. Não havendo fundamentação de verdade na arte, restaria assinalar: "Aqui houve arte". Tal posição abdica da característica de ser arte. Para Susana Scramim, a idéia de uma não-arte inclui a idéia de declínio, mas não é uma arte que nega a si mesma, porém que "convive com a idéia de sua desaparição e de seu próprio fim, criando uma passagem franca, um trânsito livre, um limiar entre 0 seu processo de vir-a-ser bem como o processo de declinar" (SCRAMIM, 2007, p. 162). Essa seria uma espécie de "potência de não-", que leva Agamben a encontrar em Bartleby o desabamento do normativo, a forma de uma potência passiva que permite 0 direito de não resposta. Bartleby, uma espécie de qualquer, é aquele ser que pode não ser - uma potência que tanto pode a potência como a impotência, exemplo de potência suprema.

Necessário, assim, pensar na literatura a partir da lógica da singularidade, aquilo que não pertence ao puro interior, nem ao puro exterior, estando assim numa lógica do confim, que pertence a todos e a ninguém. Já não imperam as imagens compactas do modernismo. Na lógica do confim, o que existe é um espaço onde circulam imagens ausentes. Esse caminho marca o abandono de uma estética vanguardista. Importante seria proliferar os confins que permitem a possibilidade de trânsito. Assim, talvez pudéssemos "des-ler" certas posições autoritárias que marcaram as vanguardas e que levaram os "acidentes" a um pelotão de fuzilamento.

A singularidade, não sendo pura, está sempre aberta a acidentes e re-contextualizações. Não se caracteriza como um conjunto de atributos intrínsecos, sendo estranha a alguém como Harold Bloom que, na afirmação do cânone, busca elencar o passado monumental de uma cultura literária. Impossível pensar na singularidade dentro de uma cultura fechada como essa.

\section{Em busca de uma outra leitura}

Ana Porrúa, no texto já citado, "Contra el Exceso", pergunta por que Lugones continua sendo lido da mesma maneira desde a década de 20, como o poeta do excesso que constitui uma falta. Poderíamos agora perguntar: Por que as leituras sobre o simbolismo fomentado no Paraná continuam sendo as mesmas leituras previstas pelo modernismo da revista Joaquim, fundamentada numa concepção de vanguarda tipicamente autoritária?

Na tentativa de formulação de uma leitura contra-modernista desse modernismo recalcado da posição de Dalton, poderíamos pensar que o que estaria em jogo no sussurro nefelibata dos simbolistas seria também uma questão filosófica e literária, já que potencializaria uma profunda reflexão sobre a própria incapacidade de levar o mundo para o texto, ou o texto para o mundo. Tal divórcio, por sua vez, não deixaria de possibilitar experiência, só que esta teria o traço da in-fans, a que se refere Agambem (2005), uma experiência anterior à própria linguagem. Assim, a questão não seria mais pautada pela crítica à falta de engajamento do nefelibata - que estaria bastante distante das questões que marcariam o modernismo autonômico -, mas seria movida por um outro pressuposto: grosso modo, a posição simbolista procurava um tipo de experiência diferente daquela prevista pelo existencialismo joaquiniano. Poderíamos assumir a assertiva de que a experiência simbolista sinaliza também para uma experiência do sujeito com o mundo, mas que não esquece que entre ambos a linguagem se afirma como potência. A possibilidade do paradoxo apresentado pela in-fans traçaria uma condição anterior ao mundo defendido por Dalton e não deixaria de ser também um reencontro com a experiência. Ou seja, o seqüestro do simbolismo se dá devido a uma recusa da sua força. É essa mesma força que permite, antes de experimentar o mundo no texto, experimentar o texto como mundo. A relação do simbolismo com a realidade é difusa, até porque a própria realidade é posta em jogo. Não caberia aqui aprofundar o debate. Resta dizer que os simbolistas não foram menos teorizadores do que os modernistas, apesar de teorizarem de uma maneira bastante diferente e menos autoritária. 0 compromisso com a experiência se refletia no compromisso com a arte. Provavelmente, encontraram na teoria das correspondências, de Baudelaire, a sua dimensão criadora. Antes de denunciar o mundo, interessaria a recriação do mundo nas imagens. Baudelaire soube demonstrar o quanto a ética moderna leva em conta o culto dessas imagens.

A condição autonômica - presente não apenas na revista de Dalton, mas em outras fiçcões modernistas - ainda preocupada com uma idéia centralizadora de identidade, gerou discursos violentos que trouxeram para a literatura a figura do Estado. 0 resultado dessa opção lembrado por Agamben é Auschwitz, a lógica do campo como paradigma da racionalidade moderna. Raul Antelo observa que a emergência do moderno, em plena época da guerra (entre politização da arte ou estetização da violência) prefigura outra guerra, a contemporânea, de dissolução dos Estados (ANTELO, 2004, p. 30-31). Susana Scramim, em Literatura do presente (2007), concordando com os pressupostos apresentados por Antelo, argumenta que os fundamentos científicos e políticos baseados em concepç̃̃es autonômicas, que não levam em conta a singularidade e as a-porias, não podem mais ser utilizados como paradigmas de práticas críticas. Esse parece ser o caso da revista curitibana. A contra-leitura seria não só uma possibilidade de "des-ler" a sua posição, mas uma possibilidade de pensá-la a partir de um regime pósautonômico, saindo assim da lógica do Estado, do centro. Também não bastaria procurar o começo, já que ele não significa origem. Também não seria suficiente, muito menos perspicaz, encontrar um pai fundador. Não há, assim, mais espaço para grandes gestos modernistas. Para finalizar, caberia perguntar: Pode um grito de vampiro abolir o sussurro de um nefelibata?

Em 1993, talvez por ironia, vampiro e nefelibata se encontram lado a lado no museu. Em comemoração aos 300 anos de história e 250 da fundação de Curitiba, a prefeitura da cidade organiza a exposição Curitiba: Tempos \& Caminhos, que reúne além de uma coleção completa da Joaquim e gravuras de Poty Lazzarotto publicadas na revista, um conjunto de peças referentes ao simbolismo, exemplares de revistas do Club Curitibano, Cenáculo e Esfinge, bem como o busto de um nefelibata seqüestrado, Dario Vellozo.

\section{Referências:}

AGAMBEN, Giorgio. Infância e História: Destruição da experiência e origem da história. Tradução de Henrique Burigo. Belo Horizonte: UFMG, 2005.

ANTELO, Raul. A aporia da leitura. I potesi, In: Revista de Estudos Literários, Juiz de Fora, v.7, n.1, 2003. (p. 31-45)

Potências da I magem. Chapecó: Argos, 2004.

BENJ AMI N, Walter. Origem do Drama Barroco Alemão. Tradução de Sério Rouanet. São Paulo: Brasiliense, 1984.

BUCH-MORSS, Susan. The Cinema Screen as prothesis of perception: an historical account. In: The Senses Still. Perception and Memory

as Material Culture in Modernity. Ed. C. Nadia Seremetakis, Chicago and London: The University of Chicago Press, 1994.

CAMPOS, Haroldo de. $\mathbf{O}$ seqüestro do barroco na formação da literatura brasileira: o caso Gregório de Mattos. 2 ed. Salvador: FCJ A, 1989. 
CANDIDO, Antonio. Formação da Literatura Brasileira: momentos decisivos. São Paulo: Martins, 1959.

. J oaquim, a irreverente e a heróica. In: Joaquim no 3. Curitiba, 1946. (p.11)

CAROLlO, Cassiana Lacerda. Decadismo e Simbolismo no Brasil. Crítica e poética. Rio de J aneiro: Livros Técnicos e Científicos; Brasília: INL, 1980. ( vol 1)

Decadismo e Simbolismo no Brasil. Crítica e poética. Rio de Janeiro: Livros Técnicos e Científicos; Brasília: INL, 1981. (vol 2)

CURITIBA, Pref. Mun: Exposição Curitiba: Tempos \& Caminhos - Catálogo. Curitiba, prefeitura Municipal, 1993. 92p

LINHARES, Temístocles. Raízes do simbolismo no Paraná. In: Joaquim no 6. Curitiba, 1946. (p.5)

MERLEAU-PONTY, Merleau. Fenomenologia da Percepção. 2 ed. Tradução de Carlos Alberto Ribeiro de Moura. São Paulo: Martins Fontes, 1999.

. Romance e Metafísica. In: Joaquim no 14. Curitiba, 1947. (p.4)

PORRÚA, Ana. Contra el exceso: lecturas del modernismo y el neobarroco en la Argentina. Texto apresentado no seminário "Políticas do Anacronismo", na Universidade Federal de Santa Catarina, Florianópolis, Brasil, 2007.

RANCIĖRE, Jacques. A partilha do sensível: estética e política. Tradução de Mônica Costa Netto. São Paulo: EXO Experimental / editora 34, 2005.

SCRAMIM, Susana. Literatura do Presente: história e anacronismo dos textos. Chapecó: Argos, 2007.

Recebido em 10/ 05/ 2008. Aprovado em 07/ 06/ 2008.

Title: The Kidnapping of Symbolism in the Magazine J oaquim: the Cry of the Vampire Against the Sighing of the Nefelibat Author: Caio Ricardo Bona Moreira

Abstract: In this essay I propose a counter-modernist reading of the radical stand by the magazine Joaquim contra 0 Simbolismo Paranaense (J oaquim Against the Symbolism of Paraná State). The magazine, created in 1946 by the writer from Curitiba, Dalton Trevisan, was published till 1948, a period of ascent of Existentialism in the postwar literary scene in the Brazilian state of Paraná. The monthly magazine refuses Symbolism, since it was considered by Dalton Trevisan as a literature, which was not tuned with his production and with man's and the world's problems. I intend to note that the issue of its genesis treated as origin by the magazine does not hold as a tool for critical practices.

Keywords: magazine Joaquim, Modernism, Symbolism in Paraná

Tìtre: La séquestration du Symbolisme dans la Revue Joaquim: Le Cri du Vampire contre le susurrement du Nefelibata Auteur: Caio Ricardo Bona Moreira

Résumé: Je propose dans cet article une lecture contre-moderniste à propos de la position radicale de la revue Joaquim contre le Symbolisme Paranaense. La revue, fondée en 1848, période de l'ascension de l'existentialisme dans le scénario littéraire du post-guerre. II se dégage de sa position autonomiste le souhait de faire débuter officiellement la littérature du Paraná. Le périodique refuse le symbolisme, puisque Dalton l'a considéré comme une littérature qui n'a pas syntonisé sa production avec les problèmes de l'homme et du monde. J'ai l'intention d'observer que la question de la genèse traitée comme origine par la revue ne se soutient pas comme fondement pour les pratiques critiques.

Mots-clés: Revue J oaquim, Modernisme, Symbolisme du Paraná

Título: El Secuestro del Simbolismo e la Revista Joaquim: el Grito del Vampiro Contra el Susurro del Nefelibata

Autor: Caio Ricardo Bona Moreira

Resumen: Propongo en este artículo una lectura contra-modernista de la posición radical de la revista Joaquim contra el Simbolismo Paranaense. La revista, fundada en 1946, por el escritor de Curitiba Dalton Trevisan, circuló hasta 1948, período de ascensión del existencialismo en el escenario literario de posguerra. Se desprende de su posición autonomista el deseo de iniciar oficialmente la literatura en Paraná. El periódico recusa el simbolismo, pues fue considerado por Dalton como una literatura que no sintonizó su producción con los problemas del hombre y del mundo. Pretendo observar que la cuestión del génesis tratado como origen por la revista no se sustenta como fundamento para prácticas críticas.

Palabras-clave: Revista J oaquim, Modernismo, Simbolismo Paranaense.

Notas:

- (Mestre em Ciências da Linguagem, pela Unisul; Doutorando em Teoria Literária, pela Universidade Federal de Santa Catarina) caiorbmoreira@hotmail.com

[1] A revista Joaquim circulou entre 1946-1948. Nos 21 números apresentados, foram publicados artigos de Antonio Candido, Mário de Andrade, Otto Maria Carpeaux, Sartre, entre outros. Contou com ilustrações de Portinari, Di Cavalcanti e Heitor dos Prazeres. Publicou também poemas inéditos de Carlos Drummond de Andrade, como O caso do vestido, e Vinícius de Moraes, em Balada do Mangue.

[2] Em vez de condenar o "nefelibata", poderíamos tomar a "nuvem" como problema. A nuvem seria um sintoma, nada gratuito, aliás, da desconstrução da matéria. Agradeço aos professores Raul Antelo e Susana Scramim pelas considerações apresentadas acerca do problema

[3] A revista foi lançada em fevereiro de 1924 e seu último número (45-46) circulou em agosto-novembro de 1927. A revista contou com colaboradores como J orge Luis Borges, Antonio Vallejo e Nicolás Olivari. O grupo inicial era formado por Evar Méndez, Samuel Glusberg, Pablo Rojas Paz, entre outros.

[4] o movimento paranista se desenvolveu em Curitiba nas décadas de 20 e 30 . o objetivo era criar uma onda regionalista. João Turin, Lange de Morretes e Ghelfi foram os artistas que fomentaram o paranismo. Tomaram a pinha, o pinhão e o pinheiro como símbolo. Esses elementos foram estampados em calçadas, paredes e quadros influenciando a arquitetura local. Quando se refere ao paranismo, Dalton Trevisan o confunde com o simbolismo.

[5] A questão é comentada por Susan Buch-Morss no texto "A tela do cinema como prótese de percepção: uma explicação histórica". Ela parte de algumas palestras apresentadas por Edmund Husserl, em 1907, em Götting, sobre "A Idéia da Fenomenologia". O objetivo principal das palestras era evidenciar um método de cognição que, enquanto mantivesse a análise 'imanente' aos conteúdos da consciência, ainda podia chegar a um conhecimento 'absoluto' e 'universal'. Susan Buch-Morss sugere que para termos uma visão precisa do objeto puro a que se refere Husserl melhor seria abandonar o texto e ir ao cinema. Isso porque as cenas do cinema, como coisa em si, trariam o traço das reduções fenomenológicas a que se refere Husserl.

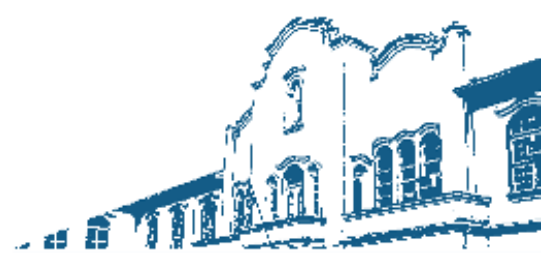


